Check for updates

Cite this: RSC Adv., 2021, 11, 33447

Received 2nd May 2021

Accepted 30th September 2021

DOI: $10.1039 / \mathrm{d} 1 \mathrm{ra03443j}$

rsc.li/rsc-advances

\title{
Direct halosulfonylation of alkynes: an overview
}

\author{
Yujun Zhang*a and Esmail Vessally (D)
}

\begin{abstract}
The difunctionalization reactions of easily available and inexpensive alkynes have emerged as a reliable, powerful, and step-economical approach for the construction of highly substituted complex alkenes in a one-pot manner, without the need for isolation of intermediates. A wide variety of transformations based on this concept have been successfully achieved for the preparation of synthetically and biologically important $\beta$-halovinyl sulfone scaffolds. In this Review, we summarize the recent advances and developments in this field and present a comprehensive overview of halosulfonylation of alkyne substrates with emphasis on the mechanistic features of the reactions.
\end{abstract}

\section{Introduction}

Sulfones $\left(\mathrm{RSO}_{2} \mathrm{R}^{\prime}\right)$ appeared as a useful and important class of organosulfur compounds due to the prevalence of this moiety in a great number of biologically active compounds ${ }^{1}$ as well as commercialized drugs, including apremilast, ceritinib, chlormezanone, dapsone, eletriptan, lifitegrast, tinidazole, and vismodegib. ${ }^{2}$ In addition, these compounds are very versatile synthetic intermediates and can function as suitable building blocks to synthesize various biologically active compounds or functional materials. ${ }^{3}$ In this family of compounds, $\beta$-halovinyl sulfones have attracted significant attention from the synthetic community because of their diverse reaction patterns and application in the assembly of various sulfonyl-substituted heterocycles ${ }^{4}$ and other value-added chemicals such as $\beta$-keto sulfones, ${ }^{5 a, b} \quad \beta$-amino sulfones, ${ }^{6} \quad$ sulfonyl-substituted $\quad 1,3$ enynes, ${ }^{7}$ acetylene sulfonyl compounds, ${ }^{8}$ 1,3-bis(arylsulfonyl) allenes $^{9}$ and many more. Therefore, it is always interesting to develop cost-effective facile synthesis strategies to prepare this special class of organosulfur compounds from easily available and inexpensive starting materials.

Recently, the direct halosulfonylation of easily accessible alkynes has emerged as an ideal strategy for the construction of the titled compounds which makes the synthetic route cleaner, greener, and faster than traditional methods that relay on the three-step sulfonation-zirconation-halogenation sequence. ${ }^{10}$ Although no reporting guideline exists for the direct fluorosulfonylation of alkynes and only a handful of methodologies have been reported for bromo-sulfonylation of alkynes, synthesis of $\beta$-chloro- and $\beta$-iodo-vinyl sulfones through the direct chloro- and iodo-sulfonylation of alkynes has been the subject of intense research efforts in recent years. In 2016, Luo

${ }^{a}$ School of Chemistry and Environmental Engineering, Hanshan Normal University, Chaozhou, 521041, Guangdong, P. R. China. E-mail: zhangyj6688@foxmail.com

${ }^{b}$ Department of Chemistry, Payame Noor University, P.O. Box 19395-3697, Tehran, Iran and co-workers published an interesting review paper entitled "recent advances in the synthesis of vinyl sulfones" that covers most of the advances in the preparation of vinyl sulfone derivatives. ${ }^{11}$ However, synthesis of $\beta$-halovinyl sulfones through the direct halosulfonylation of simple and easily accessible alkynes was almost omitted, while this procedure has recently attracted a lot of attention because of its operational simplicity and high atom and step economy. In connection with our recent reviews on the synthesis of organosulfur compounds ${ }^{12}$ and new methodologies in modern organic synthesis, ${ }^{13-20}$ herein, we provide an overview of the direct halosulfonylation of $\mathrm{C}-\mathrm{C}$ triple bonds (Fig. 1), with special emphasize on the mechanistic aspect of the reactions. For clarity, the reactions will be classified by the type of halogen atoms and sulfonylating agents.

\section{Chlorosulfonylation}

In this section, the attention is paid to the synthesis of $\beta$ chlorovinyl sulfones from the corresponding alkynes by means of the concomitant formation of $\mathrm{C}-\mathrm{S}$ and $\mathrm{C}-\mathrm{Cl}$ bonds. The section is divided into two parts according to chlorosulfonylating reagents. The first includes the chlorosulfonylation of alkynes using bifunctional reagents, while the second contains the three-component reactions.

\subsection{Two-component reactions}

The reported examples of the chlorosulfonylation of alkynes are mainly relay on the use of sulfonyl chlorides as the both sulfonylating and chlorinating agents. As early as 1971, the first

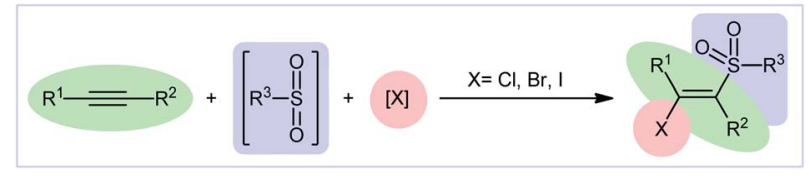

Fig. 1 Direct halosulfonylation of alkynes. 


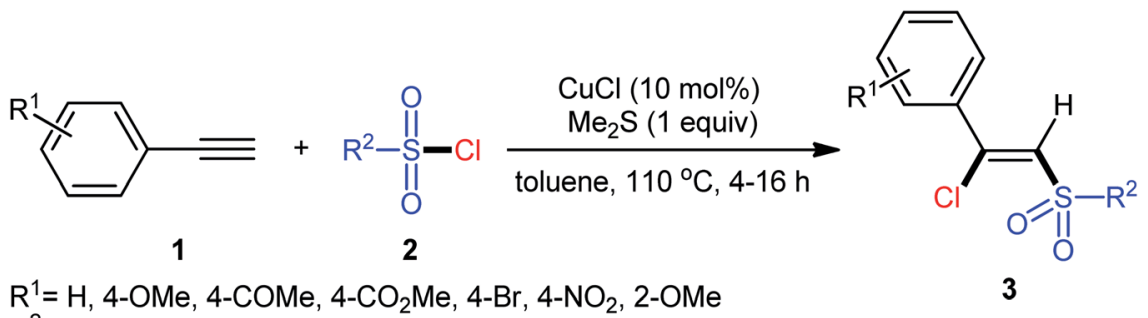

$\mathrm{R}^{2}=\mathrm{Me}, \mathrm{Ph}, 4-\mathrm{Me}-\mathrm{C}_{6} \mathrm{H}_{4}, 4-\mathrm{OMe}-\mathrm{C}_{6} \mathrm{H}_{4}$

10 examples $(52-91 \%)$

Scheme 1 Cu-catalyzed chlorosulfonylation of alkynes 1 with sulfonyl chlorides 2.

synthesis of $\beta$-chlorovinyl sulfones via the direct chlorosulfonylation of the corresponding alkynes with sulfonyl chlorides was realized by Amiel et al..$^{21,22}$ However, since then, this synthetic strategy did not attract the attention of chemists for nearly 35 years. Since last three decades, several research groups investigated the scope and limitation of this transformation. In 2005, Liang and co-workers studied the possibility of stereoselective synthesis of $\beta$-chlorovinyl sulfones through the direct $\mathrm{Cu}$-catalyzed chlorosulfonylation of phenylacetylene derivatives. ${ }^{23}$ By employing phenylacetylene and $p$-toluenesulfonyl chloride as the model substrates, the reaction variables such as catalysts, additives, and solvents were attentively screened. The results indicated that the merge of $10 \mathrm{~mol} \%$ of $\mathrm{CuCl}$ with 1 equiv. of $\mathrm{Me}_{2} \mathrm{~S}$ was the most appropriate catalytic system for this conversion and among the various aprotic solvents (e.g., THF, DMF, DCM, MeCN, toluene, dioxane); toluene was found to be the most suitable solvent. Under the optimized conditions, a diverse array of (Z)- $\beta$-chlorovinyl sulfones 3 were selectively obtained in good to excellent yields by reaction of various phenylacetylene derivatives 1 with sulfonyl chlorides 2 under an atmosphere of air at $110{ }^{\circ} \mathrm{C}$ (Scheme 1). An internal aryl-alkyl alkyne was also tested and gave the desired product but in moderate yield. The system was also amenable to the chlorosulfonylation of vinyl alkynes as exemplified by synthesis of $(Z)$-((2-chloro-2-(cyclohex-1-en-1-yl) vinyl)sulfonyl)benzene using 1-cyclohexeneacetylene as the reactant. However, diphenylacetylene, propargyl alkyl ether, and propiolate failed to participate in this transformation. The authors assumed that the $\mathrm{Me}_{2} \mathrm{~S}$ is probably involved in stabilizing the intermediate $\mathbf{A}$. Nevertheless, no comment was made by them regarding the plausible mechanistic pathway of this transformation.

Seven years later, the iron-catalyzed version of this difunctionalization reaction was disclosed by Nakamura and colleagues ${ }^{24}$ who revealed that the treatment of various aromatic and aliphatic terminal alkynes $\mathbf{4}$ with aromatic sulfonyl chlorides 5 in the presence of a combination of $\mathrm{Fe}(\mathrm{acac})_{2}(10 \mathrm{~mol} \%)$ and $(p-\mathrm{Tol})_{3} \mathrm{P}(10 \mathrm{~mol} \%)$ in refluxing

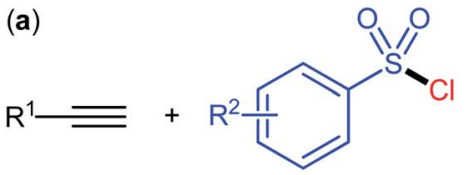

4

5

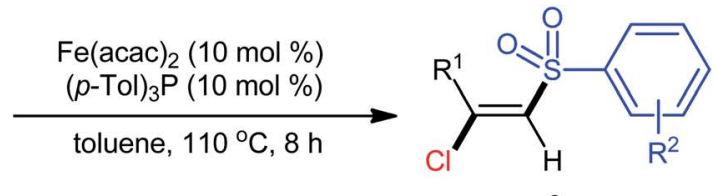

15 examples $(45-93 \%)$

$\mathrm{R}^{1}={ }^{n} \mathrm{Bu}, \mathrm{Ph} .4-\mathrm{OMe}-\mathrm{C}_{6} \mathrm{H}_{4}, 4-\mathrm{CHO}-\mathrm{C}_{6} \mathrm{H}_{4}, 4-\mathrm{F}-\mathrm{C}_{6} \mathrm{H}_{4}, 4-\mathrm{CF}_{3}-\mathrm{C}_{6} \mathrm{H}_{4}$, 3-thienyl

$\mathrm{R}^{2}=4-\mathrm{Me}, 4-\mathrm{OMe}$, 4-COMe, 4-Cl, 4-I, 4-CF $, 2-\mathrm{Me}, 2-\mathrm{Br}, 3-\mathrm{NO}_{2}-4-\mathrm{Cl}$

(b)

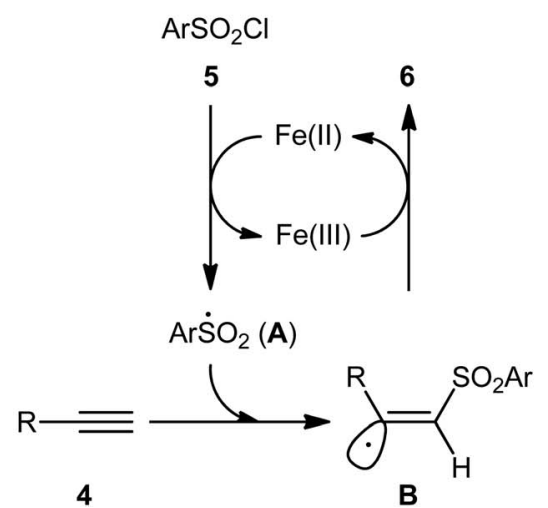

Scheme 2 (a) Fe-catalyzed chlorosulfonylation of terminal alkynes 4 with arylsulfonyl chlorides 5; (b) proposed mechanism for the formation of (E)- $\beta$-chlorovinyl sulfones 6 . 


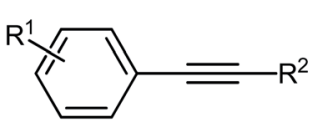

7

$\mathrm{R}^{1}={ }^{4}{ }^{\mathrm{t}} \mathrm{Bu}, 4-\mathrm{NHAc}, 4-\mathrm{NHBoc}, 4-\mathrm{NHTs}$, 4-OMe, 4-OH, 4-CO $2 \mathrm{Me}, 4-\mathrm{Br}$ $\mathrm{R}^{2}=\mathrm{Me}, \mathrm{Et},{ }^{n} \mathrm{Bu},{ }^{c} \mathrm{Hex}$

$\mathrm{R}^{3}=\mathrm{Me}, \mathrm{Et},{ }^{\mathrm{C}} \mathrm{Pr}, \mathrm{Ph}, 4-\mathrm{Me}-\mathrm{C}_{6} \mathrm{H}_{4}, 4-\mathrm{OMe}-\mathrm{C}_{6} \mathrm{H}_{4}, 4-\mathrm{F}-\mathrm{C}_{6} \mathrm{H}_{4}, 4-\mathrm{Cl}-\mathrm{C}_{6} \mathrm{H}_{4}$, 4- $\mathrm{Br}-\mathrm{C}_{6} \mathrm{H}_{4}, 3-\mathrm{Cl}-\mathrm{C}_{6} \mathrm{H}_{4}, 2-\mathrm{OMe}-5-\mathrm{Br}-\mathrm{C}_{6} \mathrm{H}_{3}, 2-\mathrm{F}-4-\mathrm{Br}-\mathrm{C}_{6} \mathrm{H}_{3}$, 2-thienyl, $4-\left(3,5-\mathrm{Me}_{2}\right)$-isoxazolyl

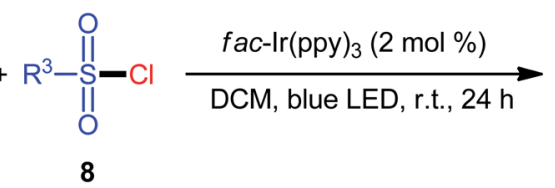

24 examples (42-90\%)

Scheme 3 Visible-light-mediated chlorosulfonylation of internal aryl-alkyl alkynes 7 with sulfonyl chlorides 8.

toluene afforded the corresponding $\beta$-chlorovinyl sulfones 6 in moderate to high yields and complete $(E)$-selectivities (Scheme 2a). According to authors proposed mechanistic pathways (Scheme $2 \mathrm{~b}$ ), this reaction proceeds through an electron transfer between iron(II) catalyst and sulfonyl chloride 5, following the radical addition of the resulting sulfonyl radical $\mathbf{A}$ to the alkyne $\mathbf{4}$ to give vinyl radical intermediate $\mathbf{B}$, which could be trapped by in situ generated iron(III) chloride to yield (E)- $\beta$ chlorovinyl sulfone derivatives $\mathbf{6}$. According to the authors, the iron(III) chloride species acts as a bulky chlorine donor and is responsible for the excellent $(E)$-selectivity for the desired products. Subsequently, a similar reaction conditions were applied by Yang and Zhu along with their colleagues to chlorosulfonylation of a diverse array of alkynyl chlorides and the desired cis-1,2-dichlorovinylsulfones were obtained in good to excellent yields, ranging from $55 \%$ to $91 \%{ }^{25}$

In 2018, Kim-Han's research group described a visible-lightmediated, fac-Ir(ppy $)_{3}$-catalyzed regio- and stereo-selective chlorosulfonylation of internal aryl-alkyl alkynes 7 with various aliphatic, aromatic, and heteroaromatic sulfonyl chlorides $8 .{ }^{26}$ This synthetic transformation exhibited an efficient and attractive method for the high yielding synthesis of $(E)-\beta$ chlorovinyl sulfone derivatives $\mathbf{9}$ at room temperature under

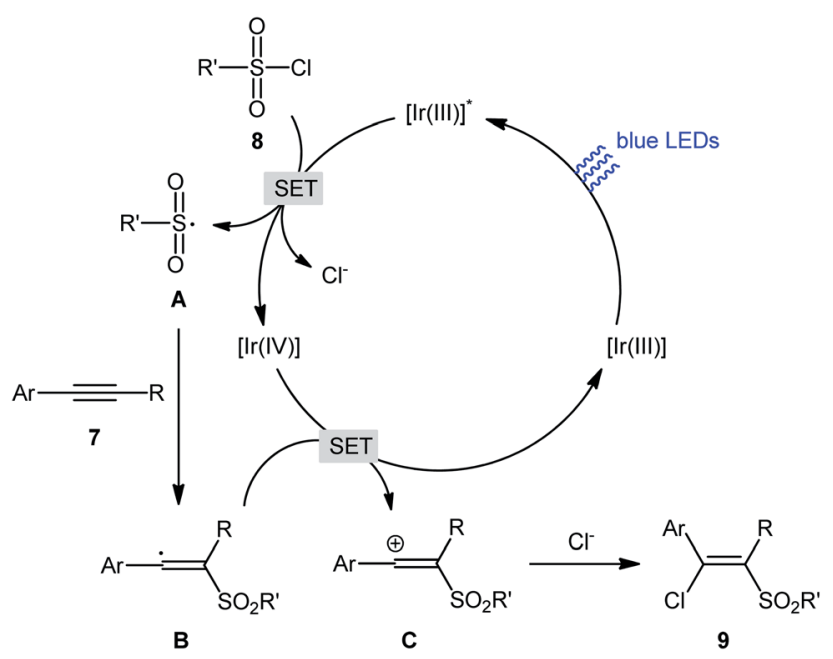

Scheme 4 Mechanistic explanation for the reaction in Scheme 3. additive-free conditions (Scheme 3). Noteworthy, the reaction exhibited high degree of regioselectivity, in which the sulfonyl group is predominantly placed on the carbon atom adjacent to the alkyl group and $\mathrm{Cl}$ group added to the carbon atom near the aryl group. Interestingly, the reaction could be conducted on gram quantities without any difficulty. This procedure was also compatible with a variety of common functional groups including fluoro, chloro, bromo, hydroxy, methoxy, amide, sulfonamide, and ester functionalities, which are useful for further functionalization. According to the authors, this transformation involves a radical mechanism as shown in Scheme 4 . In a related investigation, Reiser and co-workers reported the usefulness of well-established $\left[\mathrm{Cu}(\mathrm{dap})_{2}\right] \mathrm{Cl}$ photoredox catalyst for the direct chlorosulfonation of unsaturated hydrocarbons with sulfonyl chloride under green light irradiation. ${ }^{27}$ Thus, a small library of alkynes (terminal and internal) reacted with $p$ toluenesulfonyl chloride to give the respective $\beta$-chlorovinyl sulfone in moderate to almost quantitative yields. However, the regioselectivity of products was modest at best.

A similar strategy was then extended to a heteroleptic copper(I)-mediated chlorosulfonylation of terminal aryl alkynes $\mathbf{1 0}$ with para-fluorobenzylsulfonyl chloride $\mathbf{1 1}$ by the Hu group. ${ }^{28}$ As shown in Scheme 5, thirteen (E)-chlorosulfonylvinylbenzenes $\mathbf{1 2}$ were efficiently produced with excellent $(E)$-selectivity. However, internal aryl alkynes and aliphatic alkynes failed to undergo the reaction. It should be mentioned that the synthetic concept could also be extended to terminal alkene substrates. The authors stated that the outstanding (E)-selectivity in this difunctionalization reaction may originated from an outersphere mechanism where the radical termination step proceeds through the thermodynamically favored configuration.

\subsection{Three-component reactions}

In 2013, Xu, Li, and colleagues disclosed the preparation of $(E)$ chlorosulfonylvinylarenes $\mathbf{1 5}$ with moderate to excellent yield (up to 95\%) through iron-mediated regio- and stereo-selective chlorosulfonylation of terminal (hetero)aromatic alkynes $\mathbf{1 3}$ with arylsulfonyl hydrazides $\mathbf{1 4}$ (Scheme 6). ${ }^{29}$ The protocol uses iron(III) chloride hexahydrate as $\mathrm{Cl}$ source as well as mediator and tert-butyl hydroperoxide ( ${ }^{t} \mathrm{BuOOH}$; TBHP) as the oxidant. A series of important functional groups such as $\mathrm{F}, \mathrm{Cl}, \mathrm{Br}, \mathrm{CF}_{3}$, and 


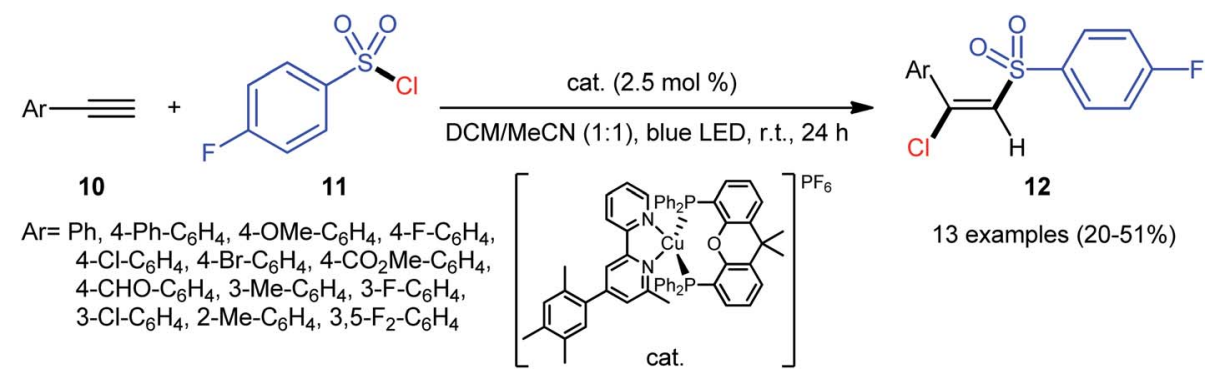

Scheme 5 Hu's synthesis of $(E)$-chlorosulfonylvinylbenzenes 12.

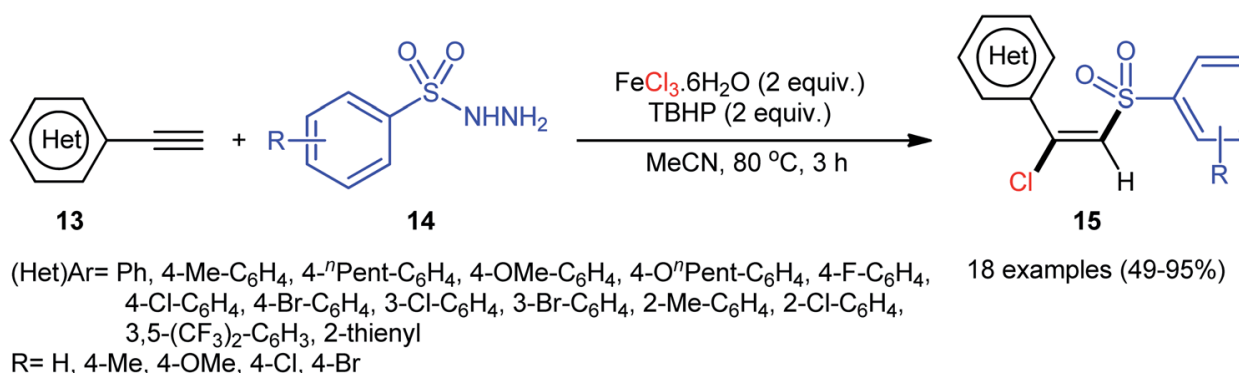

Scheme 6 Chlorosulfonylation of terminal (hetero)aromatic alkynes 13 with arylsulfonyl hydrazides 14 and $\mathrm{FeCl}_{3}$.

ether functionalities are found to be compatible under the reaction conditions. However, internal aryl alkynes were not effective in this system and applicability of alkylsulfonyl hydrazides did not investigated in this synthetic strategy. Hept1-yne did not work well in the reaction and therefore no other aliphatic alkynes were examined in the protocol. Interestingly, by replacing $\mathrm{FeCl}_{3}$ with $\mathrm{FeBr}_{3}, \beta$-bromovinyl sulfones were afforded in high yields under the identical conditions. According to the control experiments and literature reports, the authors assumed that the reaction may starts with the

$$
\begin{aligned}
& { }^{t} \mathrm{BuOOH}+\mathrm{Fe}(\mathrm{II}) \longrightarrow \mathrm{Fe}(\mathrm{III})(\mathrm{OH})+{ }^{t} \mathrm{BuO} \\
& { }^{t} \mathrm{BuOOH}+\mathrm{Fe}(\mathrm{III})(\mathrm{OH}) \stackrel{-\mathrm{H}_{2} \mathrm{O}}{\longrightarrow} \mathrm{Fe}(\mathrm{II})+{ }^{t} \mathrm{BuOO}
\end{aligned}
$$

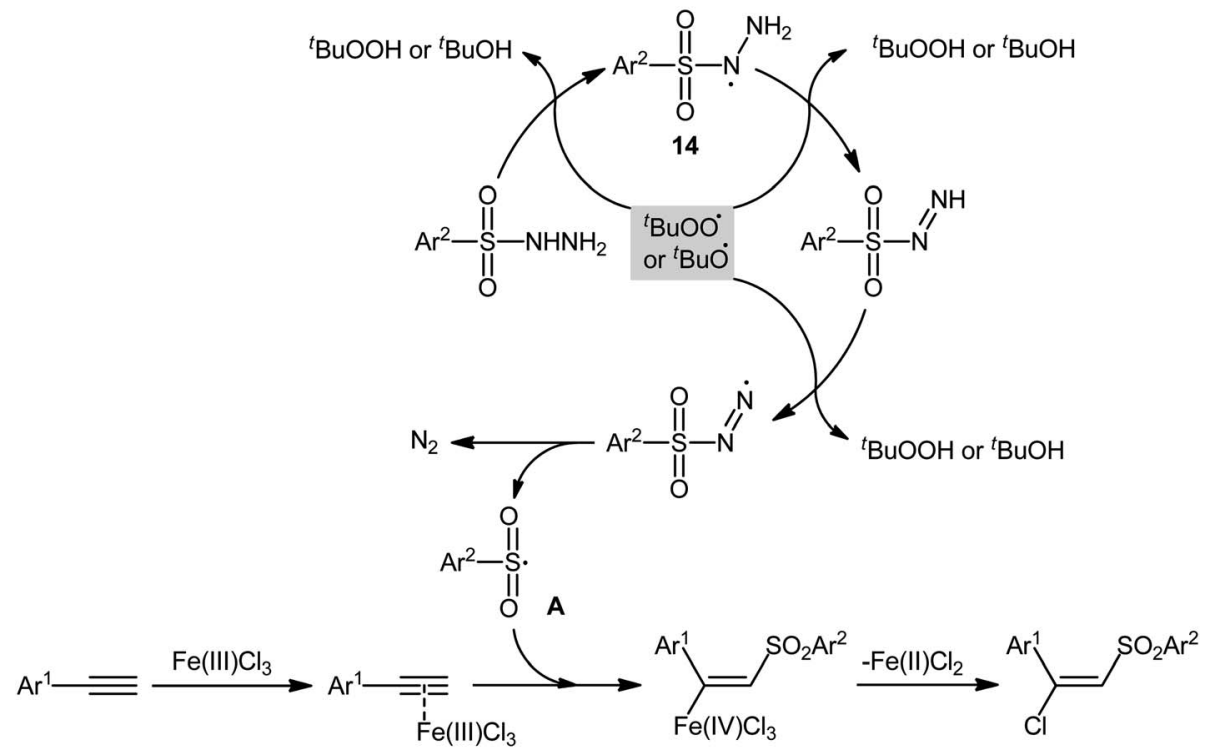

Scheme 7 Proposed Mechanism for the reaction in Scheme 6. 


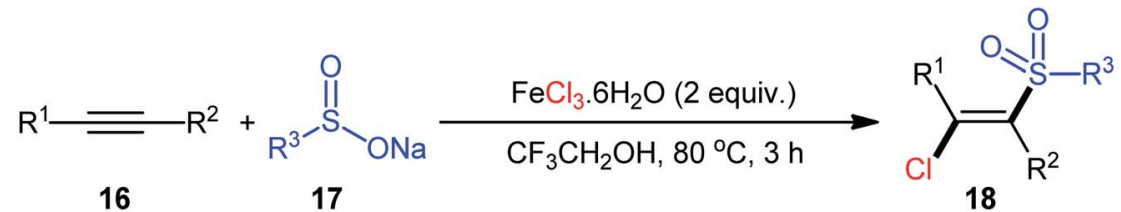

29 examples $(65-99 \%)$

$\mathrm{R}^{1}={ }^{n} \mathrm{Hex},{ }^{C} \mathrm{Hex},-\left(\mathrm{CH}_{2}\right)_{7} \mathrm{CO}_{2} \mathrm{Me},-\left(\mathrm{CH}_{2}\right)_{8} \mathrm{CO}_{2} \mathrm{H}, \mathrm{Ph}, 4-\mathrm{Me}_{-} \mathrm{C}_{6} \mathrm{H}_{4}, 4-\mathrm{F}-\mathrm{C}_{6} \mathrm{H}_{4}, 4-\mathrm{Cl}-\mathrm{C}_{6} \mathrm{H}_{4}$, 4- $\mathrm{Br}-\mathrm{C}_{6} \mathrm{H}_{4}, 4-\mathrm{CF}_{3}-\mathrm{C}_{6} \mathrm{H}_{4}, 4-\mathrm{CN}-\mathrm{C}_{6} \mathrm{H}_{4}, 4-\mathrm{COMe}-\mathrm{C}_{6} \mathrm{H}_{4}, 4-\mathrm{CO}_{2} \mathrm{Et}_{-} \mathrm{C}_{6} \mathrm{H}_{4}, 4-\mathrm{NO}_{2}-\mathrm{C}_{6} \mathrm{H}_{4}$, 3-Me- $\mathrm{C}_{6} \mathrm{H}_{4}, 3-\mathrm{Cl}-\mathrm{C}_{6} \mathrm{H}_{4}, 2-\mathrm{Me}-\mathrm{C}_{6} \mathrm{H}_{4}$, 1-naphthyl, 3-pyridyl

$\mathrm{R}^{2}=\mathrm{H}, \mathrm{Me}, \mathrm{Et}$

$\mathrm{R}^{3}=\mathrm{Me}, \mathrm{Ph}, 4-\mathrm{Me}-\mathrm{C}_{6} \mathrm{H}_{4}, 4-\mathrm{Cl}-\mathrm{C}_{6} \mathrm{H}_{4}, 4-\mathrm{Br}-\mathrm{C}_{6} \mathrm{H}_{4}, 4-\mathrm{CF}_{3}-\mathrm{C}_{6} \mathrm{H}_{4}, 4-\mathrm{NO}_{2}-\mathrm{C}_{6} \mathrm{H}_{4}, 3-\mathrm{Cl}-4-\mathrm{Me}-\mathrm{C}_{6} \mathrm{H}_{3}$, 2-naphthyl

Scheme 8 Synthesis of $(E)$ - $\beta$-chlorovinyl sulfones 18 via three-component reaction between alkynes 16 , sodium sulfinates 17 and $\mathrm{FeCl}_{3} \cdot 6 \mathrm{H}_{2} \mathrm{O}$.

generation of the tert-butoxyl and tert-butylperoxy radicals via decomposition of TBHP with the assistance of iron catalyst. Then, the resultant radicals abstract hydrogen atoms from sulfonyl hydrazide $\mathbf{1 4}$ to form sulfonyl radical $\mathbf{A}$ with the release of nitrogen. Subsequently, the selective addition of sulfonyl radical $\mathbf{A}$ to the Fe-coordinated alkyne $\mathbf{B}$ provides the $\mathrm{Fe}(\mathrm{Iv})$ intermediate $\mathbf{C}$, which after reductive elimination affords the $(E)-\beta$-halovinylsulfones $\mathbf{1 5}$ and regenerates the $\mathrm{Fe}(\mathrm{II})$ catalyst (Scheme 7).

Four years later, Chen, Yin, and co-workers reported the related chlorosulfonylation of alkynes $\mathbf{1 6}$ with sodium sulfinates 17 and $\mathrm{FeCl}_{3} \cdot 6 \mathrm{H}_{2} \mathrm{O}$ which did not require any oxidant or additive. ${ }^{30}$ The reactions were carried out in 2,2,2-trifluoroethanol at $80{ }^{\circ} \mathrm{C}$ under an inert atmosphere, tolerated both aromatic and aliphatic sodium sulfinates and various (hetero)aromatic and aliphatic terminal alkynes as well as internal aryl-alkyl alkynes, and generally delivered the expected $(E)$ - $\beta$-chlorovinyl sulfones $\mathbf{1 8}$ in good to almost quantitative yields within $3 \mathrm{~h}$ (Scheme 8). However, just like Xu-Lis' work, diaryl alkynes failed to enter into this reaction. Moreover, OMesubstituted aromatic alkynes did not respond the reaction under standard conditions.

\section{Bromosulfonylation}

After pioneering works by Amiel' $\mathrm{s}^{31}$ and Vasin' $\mathrm{s}^{32}$ research teams on bromosulfonylation of phenylacetylene with a small series of sulfonyl bromides, the first general protocol for the direct bromosulfonylation of C-C triple bonds was published in 2011 by Taniguchi et $a l^{33}$ who showed that three-component reaction between alkynes 19 , sodium sulfinates $\mathbf{2 0}$, and $\mathrm{KBr}$ in the presence of catalytic amounts of $\mathrm{CuI}$ and pby in $\mathrm{AcOH}$ under open air resulted in the formation of $(E)$ - $\beta$-bromovinyl sulfones 21 in good yields (Scheme 9). The synthetic broad scope of this methodology was established by using both aromatic and aliphatic sodium sulfinates and a library of various terminal

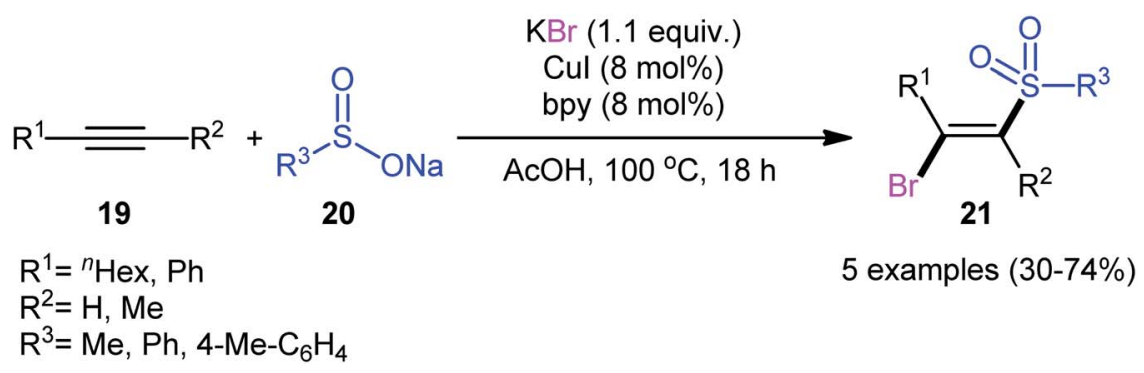

Scheme 9 Cu-catalyzed bromosulfonylation of alkynes 19 with sodium sulfinates 20 and $\mathrm{KBr}$.

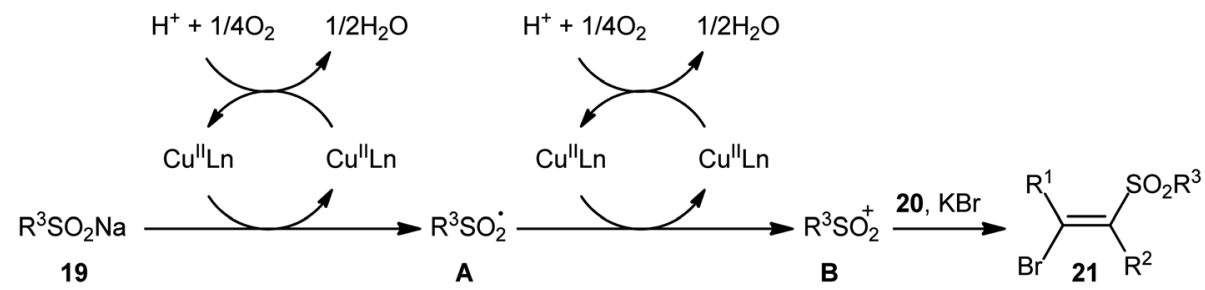

Scheme 10 Plausible reaction pathway for the formation of $(E)$ - $\beta$-bromovinyl sulfones 21 


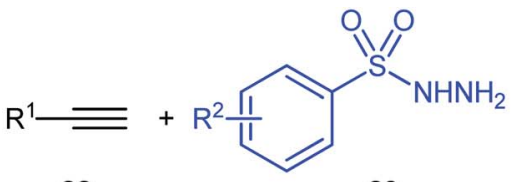

22

$\mathrm{R}^{1}={ }^{n}$ Pent, $\mathrm{Ph}, 4-\mathrm{Me}_{-} \mathrm{C}_{6} \mathrm{H}_{4}, 4-{ }^{n} \mathrm{Pent}_{-} \mathrm{C}_{6} \mathrm{H}_{4}, 4-\mathrm{OMe}-\mathrm{C}_{6} \mathrm{H}_{4}, 4-\mathrm{F}-\mathrm{C}_{6} \mathrm{H}_{4}$, 4-Cl- $\mathrm{C}_{6} \mathrm{H}_{4}, 4-\mathrm{Br}-\mathrm{C}_{6} \mathrm{H}_{4}, 3-\mathrm{Br}-\mathrm{C}_{6} \mathrm{H}_{4}, 2-\mathrm{Cl}-\mathrm{C}_{6} \mathrm{H}_{4}, 3,5-\left(\mathrm{CF}_{3}\right)_{2}-\mathrm{C}_{6} \mathrm{H}_{3}$, 2-thienyl

$\mathrm{R}^{2}=\mathrm{H}, 4-\mathrm{Me}, 4-\mathrm{OMe}, 4-\mathrm{Cl}, 4-\mathrm{Br}$

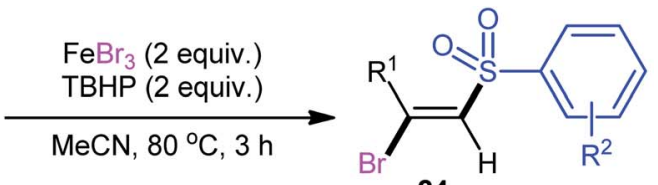

24

16 examples $(36-76 \%)$

Scheme 11 Regio- and stereo-selective synthesis of $(E)$ - $\beta$-bromovinyl sulfones 24 reported by Li and $\mathrm{Xu}$.

and aryl-alkyl internal alkynes. However, alkyl-alkyl internal alkynes did not work well in this process and aryl-aryl internal alkynes were quite inert under standard conditions. A plausible mechanism for this $\mathrm{Cu}$-catalyzed difunctionalization reaction was suggested by the authors, as shown in Scheme 10. It involved single-electron oxidation of sodium sulfinate 20 by in situ generated $\mathrm{Cu}$ (II) species to generate the sulfonyl radical $\mathbf{A}$, which was then experienced the second oxidation to furnish sulfonyl cation B. Finally, this intermediate underwent stereoselective anti-addition to alkyne $\mathbf{1 9}$ to form the target product 21.

In 2013, in the same paper describing the direct chlorosulfonylation of alkynes with arylsulfonyl hydrazides as the sulfonyl precursor and $\mathrm{FeCl}_{3}$ as the chloride source in the presence of TBHP, $\mathrm{Li}$ and $\mathrm{Xu}$ reported the successful $\mathrm{FeBr}_{3}$ mediated preparation of (E)- $\beta$-bromovinyl sulfones $\mathbf{2 4}$ from alkynes 22 and sulfonyl hydrazides 23 (Scheme 11). ${ }^{29}$ Generally, bromosulfonylation exhibited relatively poorer reactivity compared to chlorosulfonylation. The authors speculated that the difference in the reactivity between chlorosulfonylation and bromosulfonylation might result from the easier abstraction of $\mathrm{Br}$ than $\mathrm{Cl}$ by sulfonyl radicals. Of note, the formation of both sulfonyl chloride and bromide by-products was detected in the halosulfonylation.

Following these works, $\mathrm{Wu}$ and Jiang along with their coworkers reported an effective metal-free bromosulfonylation reaction of terminal alkynes 25 with sodium arylsulfinates $26 .{ }^{27}$ This difunctionalization reaction, accomplished with 1 equiv. of $N$-bromosuccinimide (NBS) as both a trigger and a bromine source, exhibited high reactivity and broad substrate scope with respect to both alkynes and sodium sulfinates. Twenty-one $\beta$ - bromovinyl sulfones 27 were synthesized in good yields (76$88 \%)$ and excellent regio- and stereoselectives under the reaction conditions (Scheme 12). This procedure was further successfully applied to the synthesis of $(E)$ - $\beta$-iodovinyl sulfones by using NIS instead of NBS. The authors also investigated the synthetic utility of the prepared compounds as electrophilic coupling partners in Suzuki and Sonogashira cross-coupling reactions.

\section{Iodosulfonylation}

In this section we would like to focus on the direct introduction of iodine and sulfonyl groups into alkynes. Note that the section is divided into two major sub-sections according to iodosulfonylating reagents. The first includes the iodosulfonylation of alkyne substrates using bifunctional reagents, while the second contains the three-component reactions.

\subsection{Two-component reactions}

In 1971, Truce and Wolf reported the first example of the direct iodosulfonylation of alkynes 28 employing sulfonyl iodides 29 as both the iodine and sulfonyl sources. ${ }^{35}$ The reaction was run under irradiation of visible light in the absence of any catalyst or oxidant, tolerated various terminal and internal alkynes, and generally provided $(E)$ - $\beta$-iodovinyl sulfone products 30 in relatively poor to high yields as exclusively Markovnikov regioisomers (Scheme 13). Analysis by X-ray diffraction clearly indicated that the stereochemistry of the products was $E$. Concerning the substrate scope, the reaction was highly dependent on the steric- and electronic-factors of both substrates. Generally, sterically less hindered sulfonyl iodides

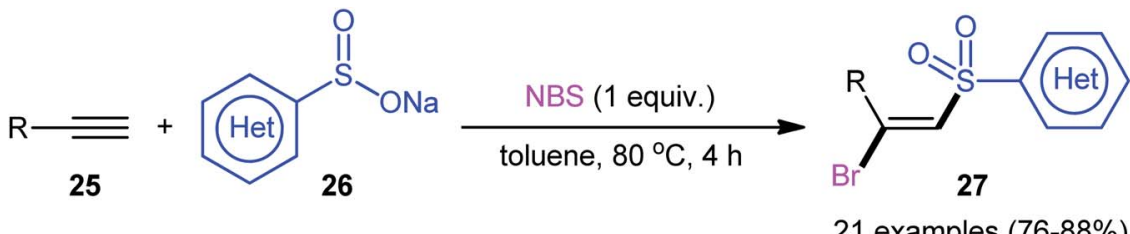

$\mathrm{R}={ }^{n} \mathrm{Hex},{ }^{n} \mathrm{Hex},-\left(\mathrm{CH}_{2}\right)_{2} \mathrm{CH}_{2} \mathrm{CN},-\mathrm{CH}_{2} \mathrm{Bn}, \mathrm{Ph}, 4-\mathrm{Me}_{-} \mathrm{C}_{6} \mathrm{H}_{4}, 4-{ }^{t} \mathrm{Bu}-\mathrm{C}_{6} \mathrm{H}_{4}, 4-\mathrm{Ph}-\mathrm{C}_{6} \mathrm{H}_{4}$, 4-OMe- $\mathrm{C}_{6} \mathrm{H}_{4}, 4-\mathrm{F}-\mathrm{C}_{6} \mathrm{H}_{4}, 4-\mathrm{Cl}-\mathrm{C}_{6} \mathrm{H}_{4}, 4-\mathrm{Br}-\mathrm{C}_{6} \mathrm{H}_{4}, 3-\mathrm{Me}-\mathrm{C}_{6} \mathrm{H}_{4}, 2,4-\mathrm{Me}_{2}-\mathrm{C}_{6} \mathrm{H}_{3}$, 3-pyridyl (Het)Ar= $\mathrm{Ph}, 4-\mathrm{F}-\mathrm{C}_{6} \mathrm{H}_{4}, 4-\mathrm{Cl}-\mathrm{C}_{6} \mathrm{H}_{4}, 4-\mathrm{Br}_{-} \mathrm{C}_{6} \mathrm{H}_{4}, 2$-naphthyl, 2-thienyl

Scheme 12 Catalyst-free direct bromosulfonylation of terminal alkynes 25 with sodium arylsulfinates 26 employing NBS as the bromine source. 
<smiles>[R][R7]C#C[R]</smiles>
$\mathrm{CO}_{2} \mathrm{Et}, \mathrm{COPh}, \mathrm{Ph}, 4-\mathrm{Me}-\mathrm{C}_{6} \mathrm{H}_{4}$

20 examples $(15-87 \%)$ $\mathrm{R}^{2}=\mathrm{H}, \mathrm{Et}, \mathrm{Ph}, \mathrm{Cl}$

$\mathrm{R}^{3}=\mathrm{Me}, \mathrm{Et},{ }^{i} \mathrm{Pr},{ }^{t} \mathrm{Bu}, 4-\mathrm{Me}-\mathrm{C}_{6} \mathrm{H}_{4}$

Scheme 13 Truce's synthesis of $(E)$ - $\beta$-iodovinyl sulfones 30 .

gave higher yields as compared to bulkier sulfonyl iodides. The relative reaction rates of alkynes in this transformation followed the order: terminal aromatic alkynes $\geq$ terminal aliphatic alkynes $\approx$ internal alkyl-alkyl alkynes $\gg$ internal aryl-aryl alkynes $>$ propiolates $>$ propiolonitriles. It is noteworthy that the authors applied the prepared iodovinyl sulfones as starting materials in high yielding synthesis of acetylenic sulfones via simple dehydrohalogenation by treatment with $\mathrm{K}_{2} \mathrm{CO}_{3}$ in methanol-water.

Sixteen years later, Corréa and co-workers reported further examples of $\beta$-iodovinyl sulfones synthesis under Truce's standard reaction condition. ${ }^{36}$ Although, the story of direct iodosulfonylation of $\mathrm{C}-\mathrm{C}$ triple bonds was began by using sulfonyl iodides as bifunctional iodosulfonylating reagents, the instability of these compounds greatly limited the application of this method to construct $\beta$-iodovinyl sulfones. ${ }^{37}$

\subsection{Three-component reactions}

4.2.1. Sodium sulfinates as sulfonylation agents. As early as in the beginning of the 2000s, Nair and co-workers observed the formation of $(E)$ - $\beta$-iodovinyl sulfones by cerium(Iv) ammonium nitrate(CAN)-mediated direct iodosulfonylation of phenylacetylene derivatives with sodium arylsulfinates and sodium iodide. ${ }^{38,39}$ Later, Wu-Jiang's research group reported a catalystfree iodosulfonylation reaction via three-component reaction of a small library of terminal aromatic alkynes 31, sodium $p$-toluenesulfinate 32, and $N$-iodosuccinimide (NIS). ${ }^{34}$ The reaction proceeds with excellent regio- and stereoselectivity to afford $(E)$ $\beta$-iodovinyl sulfones 33 in high yields, ranging from $86 \%$ to $89 \%$ (Scheme 14).

In 2017, with the objective of designing a milder and greener procedure to $\beta$-iodovinyl sulfones through iodosulfonylation of the respective alkynes, Sun and Liu along with their colleagues

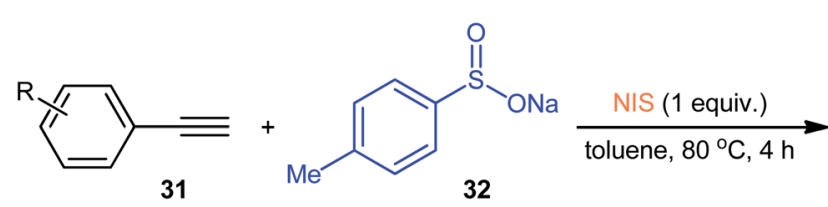

$\mathrm{R}=\mathrm{H}, 4-\mathrm{F}, 4-\mathrm{Cl}, 3,5-\left(\mathrm{CF}_{3}\right)_{2}$

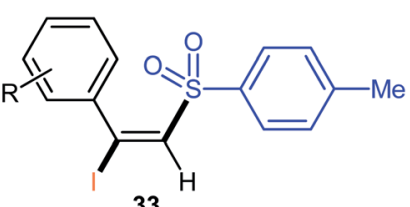

4 examples $(86-89 \%)$

Scheme 14 Catalyst-free iodosulfonylation of terminal aromatic alkynes 31 with sodium $p$-toluenesulfinate 32 and NIS.

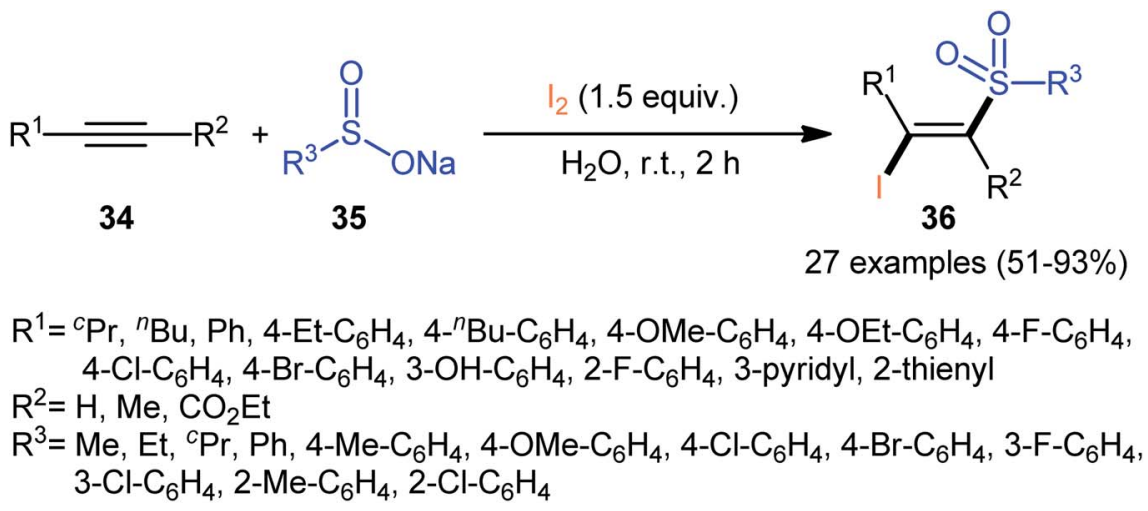

Scheme 15 Catalyst-free synthesis of $(E)$ - $\beta$-iodovinyl sulfones 36 via the reaction of alkynes 34 with sodium sulfinates 35 and $I_{2}$. 


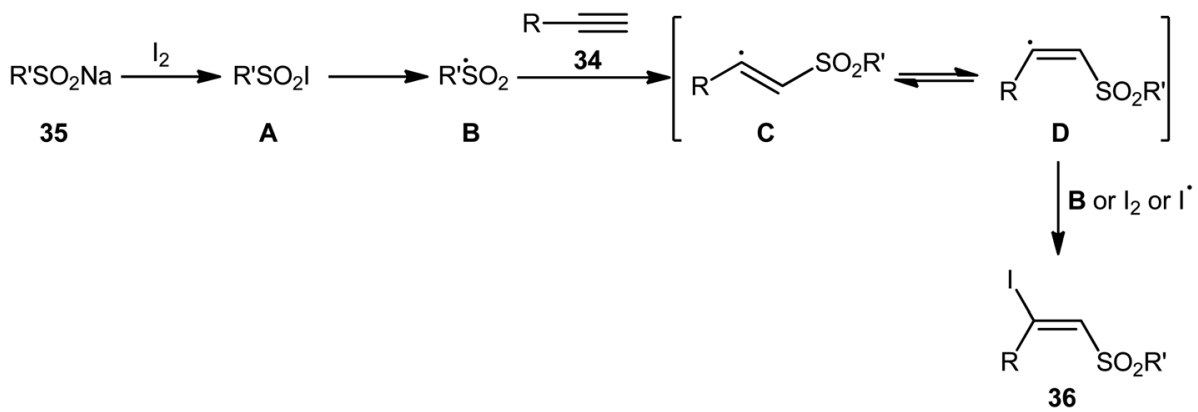

Scheme 16 A proposed pathway for the formation of $(E)$ - $\beta$-iodovinyl sulfones 36

were able to demonstrated that a diverse range of $(E)$ - $\beta$-iodovinyl sulfones 36 could be obtained in moderate to excellent yields from the reaction of alkynes $\mathbf{3 4}$ (terminal and internal) with sodium sulfinates 35 (aromatic and aliphatic) and molecular iodine in the most environmentally friendly solvent, water, at room temperature under catalyst- and additive-free conditions (Scheme 15). ${ }^{40}$ In addition, a scale-up experiment $(20 \mathrm{mmol}$ scale) and a few synthetic applications based on the known cross-coupling reactions highlighted the usefulness of this methodology. A few control experiments were carried out to gain mechanistic insights for this appealing reaction. With the use of the radical scavenger butylated hydroxytoluene (BHT), no prohibition of the reaction was occurred. However, the reaction was completely inhibited in the presence of 2,2,6,6tetramethylpiperidine-1-oxyl (TEMPO), which indicated that the reaction presumably underwent a radical pathway (Scheme 16). Initially, a sulfonyl iodide intermediate $\mathbf{A}$ was formed via the reaction of sulfinate sodium salt 35 with iodine. In the next step, this intermediate $\mathbf{A}$ underwent homolytic cleavage and a sulfonyl radical $\mathbf{B}$ along with an iodine radical was generated. Thereafter, the newly formed radical $\mathbf{B}$ was added chemoselectively to the alkyne $\mathbf{3 4}$ and provided the vinyl sulfone radicals $\mathbf{C}$ and $\mathbf{D}$. Finally, electrophilic addition of $\mathrm{I}^{\bullet}$ the vinyl sulfone radical $\mathbf{D}$ gave the desired product $\mathbf{3 6}$. Subsequently, Bi and co-workers slightly improved the efficiency of this reaction in the term of product yields by performing the process in the presence of 2 equiv. of di-tert-butyl peroxide (DTBP) as an oxidant in the binary solvent $\mathrm{EtOH} / \mathrm{H}_{2} \mathrm{O}$ with ratio $1: 1$ at $60{ }^{\circ} \mathrm{C} .{ }^{41}$

Based on these developments, Reddy and co-workers developed a metal-free iodosulfonylation reaction of acetylenic ketones $\mathbf{3 7}$ using sodium sulfinates $\mathbf{3 8}$ and molecular iodine as the sulfonyl and iodine sources, respectively. ${ }^{42}$ In the presence of TBHP as oxidant, a wide range of internal acetylenic ketones successfully underwent the reaction to generate polyfunctional tetrasubstituted olefins 39 in moderate to excellent yields with complete regio- and stereoselectively (Scheme 17). Regarding the regioselectivity of this transformation, in all examples the sulfonyl group selectively attacked to the carbon atom adjacent to the carbonyl group and iodine placed on the carbon atom near the aryl/alkyl substituents. A wide range of functionalities both in the acetylenic ketones and sodium sulfinates were well tolerated with these reaction conditions. However, nitrosubstituted sodium arylsulfinates did not respond this reaction. Recently, the Zhang-Xie group successfully extended this chemistry to propargyl alcohols using a 1:2 mixture of $\mathrm{ClCH}_{2} \mathrm{CH}_{2} \mathrm{Cl}: \mathrm{H}_{2} \mathrm{O}$ as the reaction medium. ${ }^{43}$ Noteworthy, the reaction proceeded effectively without addition of any catalyst or oxidant, ultimately minimizing the production of waste streams.

In 2018, Taniguchi reported that cobalt salts could act as efficient catalysts for iodosulfonylation reactions of alkynes with sodium sulfinates in which potassium iodide (KI) was used as iodination reagent. ${ }^{44}$ Among the various cobalt catalysts like<smiles>[R]C#CC([R])=O</smiles>

$\mathrm{R}^{1}={ }^{n} \mathrm{Pr},{ }^{i} \mathrm{Bu},{ }^{C} \mathrm{Hex},-\mathrm{CH}(\mathrm{NHTs}) \mathrm{CHMe}_{2}, \mathrm{Ph}, 4-\mathrm{OEt}-\mathrm{C}_{6} \mathrm{H}_{4}, 4-\mathrm{F}-\mathrm{C}_{6} \mathrm{H}_{4}, 4-\mathrm{Br}-\mathrm{C}_{6} \mathrm{H}_{4}, 3-\mathrm{OPh}-\mathrm{C}_{6} \mathrm{H}_{4}$, 3-Cl- $\mathrm{C}_{6} \mathrm{H}_{4}, 3,4-(\mathrm{OMe})_{2}-\mathrm{C}_{6} \mathrm{H}_{3}$, 2-naphthyl, 3-pyridyl, 2-thienyl, 3-furyl, 3-(N-Bn)-indolyl $\mathrm{R}^{2}=\mathrm{Ph}, 4-\mathrm{Me}-\mathrm{C}_{6} \mathrm{H}_{4}, 4-{ }^{\mathrm{t}} \mathrm{Bu}-\mathrm{C}_{6} \mathrm{H}_{4}, 4-\mathrm{OMe}-\mathrm{C}_{6} \mathrm{H}_{4}, 4-\mathrm{COMe}-\mathrm{C}_{6} \mathrm{H}_{4}, 4-\mathrm{CO}_{2} \mathrm{Me}^{-} \mathrm{C}_{6} \mathrm{H}_{4}, 4-\mathrm{NO}_{2}-\mathrm{C}_{6} \mathrm{H}_{4}$, 4- $-\mathrm{C}_{6} \mathrm{H}_{4}, 3-\mathrm{Me}^{-} \mathrm{C}_{6} \mathrm{H}_{4}, 3-\mathrm{Cl}-\mathrm{C}_{6} \mathrm{H}_{4}, 2-(6-\mathrm{Me})$-naphthyl, 3-thienyl

$\mathrm{R}^{3}=\mathrm{Me}, \mathrm{Ph}, 4-\mathrm{Me}-\mathrm{C}_{6} \mathrm{H}_{4}, 4-\mathrm{F}-\mathrm{C}_{6} \mathrm{H}_{4}, 4-\mathrm{Cl}-\mathrm{C}_{6} \mathrm{H}_{4}$ 


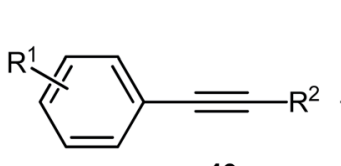

40

$\mathrm{R}^{1}=\mathrm{Ph}, 4-\mathrm{Me}, 4-\mathrm{Ph}, 4-\mathrm{OMe}, 4-\mathrm{F}, 2-\mathrm{Me}$

$\mathrm{R}^{2}=\mathrm{H}, \mathrm{Me}, \mathrm{Et}, \mathrm{CH}_{2} \mathrm{OAC}$

$\mathrm{R}^{3}=\mathrm{Me}, \mathrm{Ph}, 4-\mathrm{Me}-\mathrm{C}_{6} \mathrm{H}_{4}, 4-\mathrm{OMe}-\mathrm{C}_{6} \mathrm{H}_{4}, 4-\mathrm{F}-\mathrm{C}_{6} \mathrm{H}_{4}$, 4-Cl- $\mathrm{C}_{6} \mathrm{H}_{4}, 4-\mathrm{NHAC}-\mathrm{C}_{6} \mathrm{H}_{4}$, 1-naphthyl

41
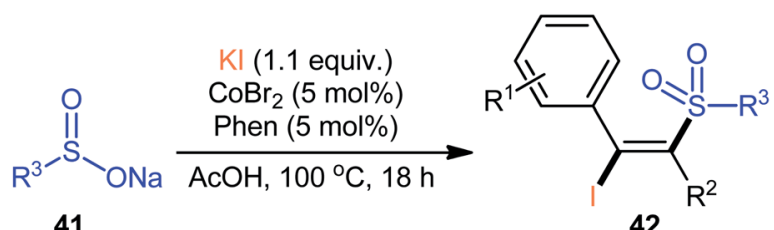

42

17 examples (38-87\%)

Scheme 18 Co-catalyzed iodosulfonylation of alkynes 40 with sodium sulfinates 41 and Kl.

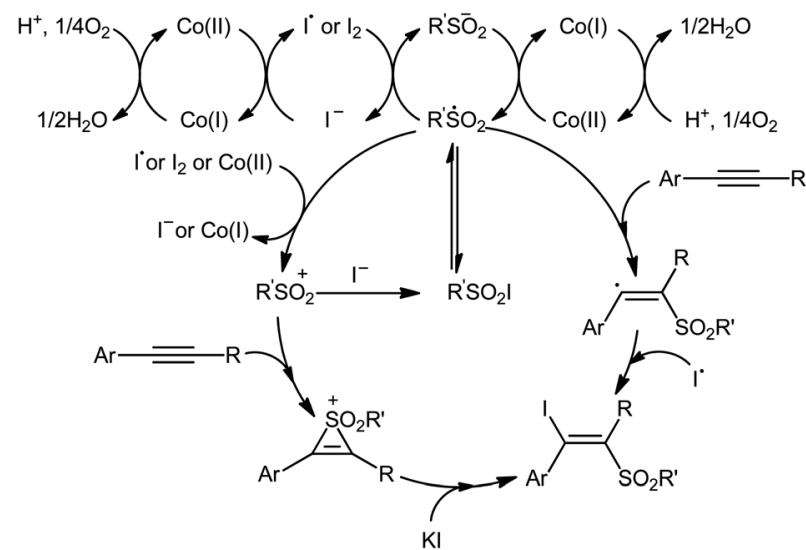

Scheme 19 The proposed mechanism for the reaction in Scheme 18.

$\mathrm{CoCl}_{2}, \mathrm{CoBr}_{2}, \mathrm{Co}(\mathrm{OAc})_{2}$; low-cost $\mathrm{CoBr}_{2}$ was the most efficient for the transformation. In the presence of $5 \mathrm{~mol} \%$ of $\mathrm{CoBr}_{2}$ and $5 \mathrm{~mol} \%$ of Phen $\cdot \mathrm{H}_{2} \mathrm{O}$ (Phen = phenanthroline) in AcOH under air, a library of aromatic terminal and aryl-alkyl internal alkynes 40 smoothly underwent iodosulfonylation with sodium aryl/alkyl-sulfinates $\mathbf{4 1}$ and KI to give structurally diverse $(E)$ - $\beta$ iodovinyl sulfones $\mathbf{4 2}$ in modestly to high yields (Scheme 18). It should be mentioned that iodosulfonylation of a vinylacetylene was also achieved with use of similar reaction conditions. However, this synthetic strategy was found not to be applicable to terminal alkyl and internal aryl-aryl alkynes. Interestingly, when the reaction was performed in the absence of sodium sulfinates, the corresponding diiodoalkenes were obtained in high yields. The mechanism proposed for the formation of $\beta$ iodovinyl sulfones is depicted in Scheme 19.

4.2.2. Sulfonyl hydrazides as sulfonylation agents. In 2013, $\mathrm{Li}$-Xu's group reported the first iodosulfonylation of alkynes with sulfonyl hydrazides and molecular iodine. ${ }^{45}$ In this work, a regio- and stereoselective iodosulfonylation reaction occurs in the presence of TBHP as the oxidant. A wide range of (hetero) aromatic terminal alkynes $\mathbf{4 3}$ could be reacted with arylsulfonyl hydrazides $\mathbf{4 4}$ under the optimized conditions to give the $(E)-\beta$ iodovinyl sulfone products $\mathbf{4 5}$ in moderate to almost quantitative yields (Scheme 20a). Aliphatic terminal alkynes, such as hept-1-yne, could also be reacted under the identical conditions. However, the desired products were obtained in poor yields. The authors proposed a mechanism analogous to that of their chlorosulfonylation strategy. Drawing inspiration from this work, Yang and co-workers reported the synthesis of a library of (E)- $\beta$-iodovinyl sulfone products 48 shown in

(a)

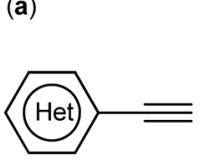

43<smiles>NNS(=O)(=O)c1[c-][c]ccc1</smiles>

44

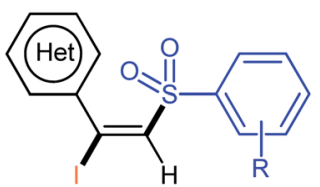

45

(Het)Ar= Ph, 4-Me- $\mathrm{C}_{6} \mathrm{H}_{4}, 4-\mathrm{CPent}_{-} \mathrm{C}_{6} \mathrm{H}_{4}, 4-\mathrm{OMe}_{-} \mathrm{C}_{6} \mathrm{H}_{4}, 4-\mathrm{F}-\mathrm{C}_{6} \mathrm{H}_{4}, 4-\mathrm{Cl}_{-} \mathrm{C}_{6} \mathrm{H}_{4}, \quad 13$ examples (56-94\%) 4- $-\mathrm{Br}_{-}-\mathrm{C}_{6} \mathrm{H}_{4}, 2-\mathrm{Cl}-\mathrm{C}_{6} \mathrm{H}_{4}, 3,5-\left(\mathrm{CF}_{3}\right)_{2}-\mathrm{C}_{6} \mathrm{H}_{3}, 3$-pyridyl, 2-thienyl $\mathrm{R}=\mathrm{H}, 4-\mathrm{Me}, 4-\mathrm{Br}$

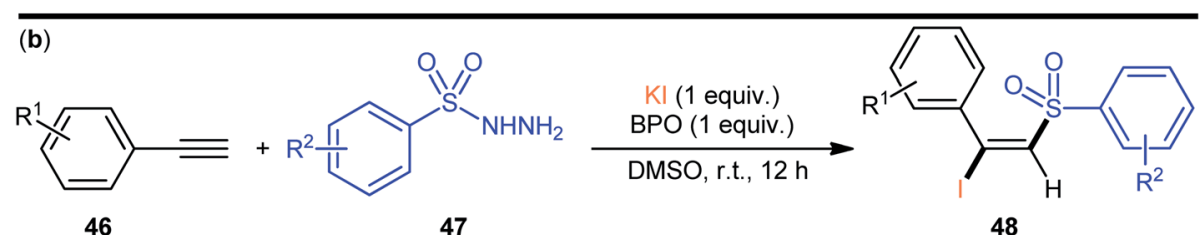

$\mathrm{R}^{1}=\mathrm{H}, 4-\mathrm{Me}, 4-\mathrm{OMe}, 4-\mathrm{F}, 4-\mathrm{Cl}, 3-\mathrm{Me}, 2-\mathrm{F}$

$\mathrm{R}^{2}=\mathrm{H}, 4-\mathrm{Me}, 4-\mathrm{OMe}, 4-\mathrm{Cl}, 4-\mathrm{CN}, 3,4-(\mathrm{CH}=\mathrm{CH})_{2}-$

16 examples $(66-88 \%)$

Scheme 20 (a) TBHP-mediated iodosulfonylation of terminal alkynes 43 with arylsulfonyl hydrazides 44 and $I_{2}$; (b) BPO-mediated threecomponent reaction between alkynes 46 , arylsulfonyl hydrazides 47 , and $\mathrm{Kl}$. 


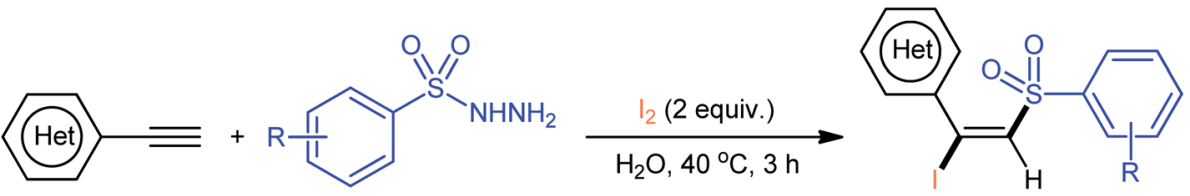

49

50

51

(Het)Ar= Ph, 4- ${ }^{n}$ Pent- $\mathrm{C}_{6} \mathrm{H}_{4}, 4-\mathrm{OMe}-\mathrm{C}_{6} \mathrm{H}_{4}, 4-\mathrm{F}-\mathrm{C}_{6} \mathrm{H}_{4}$

4- $\mathrm{Cl}-\mathrm{C}_{6} \mathrm{H}_{4}, 3-\mathrm{F}-\mathrm{C}_{6} \mathrm{H}_{4}, 2-\mathrm{Cl}-\mathrm{C}_{6} \mathrm{H}_{4}$, 2-thienyl

$\mathrm{R}=\mathrm{H}, \mathrm{Me}, 4-\mathrm{OMe}$, 4-COMe, 4-F-, 4-Cl, 4- $\mathrm{Br}, 4-\mathrm{NO}_{2}$,

4-NHCOMe, 2-Me, 2-F, 3,5- $\mathrm{Cl}_{2}, 2,4,6-\mathrm{Me}_{3}, 3,4-(\mathrm{CH}=\mathrm{CH})_{2}-, 3-\mathrm{Cl}-4,6-\mathrm{F}_{2}$

23 examples $(30-85 \%)$

Scheme 21 Catalyst-free iodosulfonylation of alkynes 49 with arylsulfonyl hydrazides 50 and $\mathrm{I}_{2}$ in water.

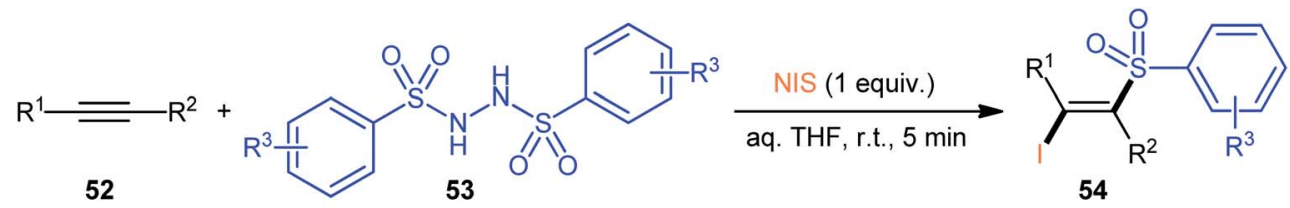

$\mathrm{R}^{1}={ }^{9} \mathrm{Hex}, \mathrm{Ph}, 4-\mathrm{Me}-\mathrm{C}_{6} \mathrm{H}_{4}, 4-\mathrm{Et}_{-} \mathrm{C}_{6} \mathrm{H}_{4}, 4-\mathrm{Ph}-\mathrm{C}_{6} \mathrm{H}_{4}, 4-\mathrm{OMe}-\mathrm{C}_{6} \mathrm{H}_{4}, 4-\mathrm{F}-\mathrm{C}_{6} \mathrm{H}_{4}$,

4-Cl- $\mathrm{C}_{6} \mathrm{H}_{4}, 4-\mathrm{Br}-\mathrm{C}_{6} \mathrm{H}_{4}, 3-\mathrm{Me}-\mathrm{C}_{6} \mathrm{H}_{4}, 3-\mathrm{F}-\mathrm{C}_{6} \mathrm{H}_{4}, 2-\mathrm{F}-\mathrm{C}_{6} \mathrm{H}_{4}, 2$-pyridyl

26 examples $(32-95 \%)$

$\mathrm{R}^{2}=\mathrm{H}, \mathrm{Me}, \mathrm{CO}_{2} \mathrm{Et}, \mathrm{CH}_{2} \mathrm{OH}, \mathrm{Ph}$

$\mathrm{R}^{3}=\mathrm{H}, 4-\mathrm{Me}, 4-\mathrm{NO}_{2}, 4-\mathrm{F}, 4-\mathrm{Cl}, 4-\mathrm{Br}, 3,4-(\mathrm{CH}=\mathrm{CH})_{2}^{-}$

Scheme 22 Synthesis of (E)- $\beta$-iodovinyl sulfones 54 via the reaction of alkynes 52 with $N, N^{\prime}$-disulfonylhydrazines 53 and NIS.

Scheme $20 \mathrm{~b} .{ }^{46}$ These compounds were formed by reaction of the corresponding alkynes 46 with arylsulfonyl hydrazides 47 using $\mathrm{KI}$ as iodine source and benzoic peroxyanhydride (BPO) as an oxidant. Subsequently, Tong et al. utilized TBAI as iodine source, and developed a $\mathrm{K}_{2} \mathrm{~S}_{2} \mathrm{O}_{8}$-mediated reaction of alkynes with sulfonyl hydrazides for the stereoselective synthesis of $(E)$ $\beta$-iodovinyl sulfones. ${ }^{47}$

Following these works, an elegant catalyst- and additive-free reaction of preparing $(E)$ - $\beta$-iodovinyl sulfone scaffolds $\mathbf{5 1}$ from terminal aromatic alkynes $\mathbf{4 9}$, arylsulfonyl hydrazides 50, and molecular iodine using environmentally benign water as the solvent under room temperature was demonstrated by Wang and Yan (Scheme 21). ${ }^{37}$ The results indicated that the phenylacetylenes with electron-donating substituents gave higher yields compared to the electron-withdrawing group containing phenylacetylenes. Unfortunately, the alkynes bearing nitrosubstitution were incompatible in this transformation. Intriguingly, the electronic character of the substituents on the arylsulfonyl hydrazides had a little impact on the rate of this reaction. However, nitro-substituted arylsulfonyl hydrazides did not work well in the methodology. The mechanism investigation of the reaction using the radical scavengers indicated that a radical pathway could be involved. Shortly afterwards, Sun and co-workers extended the substrate scope of this

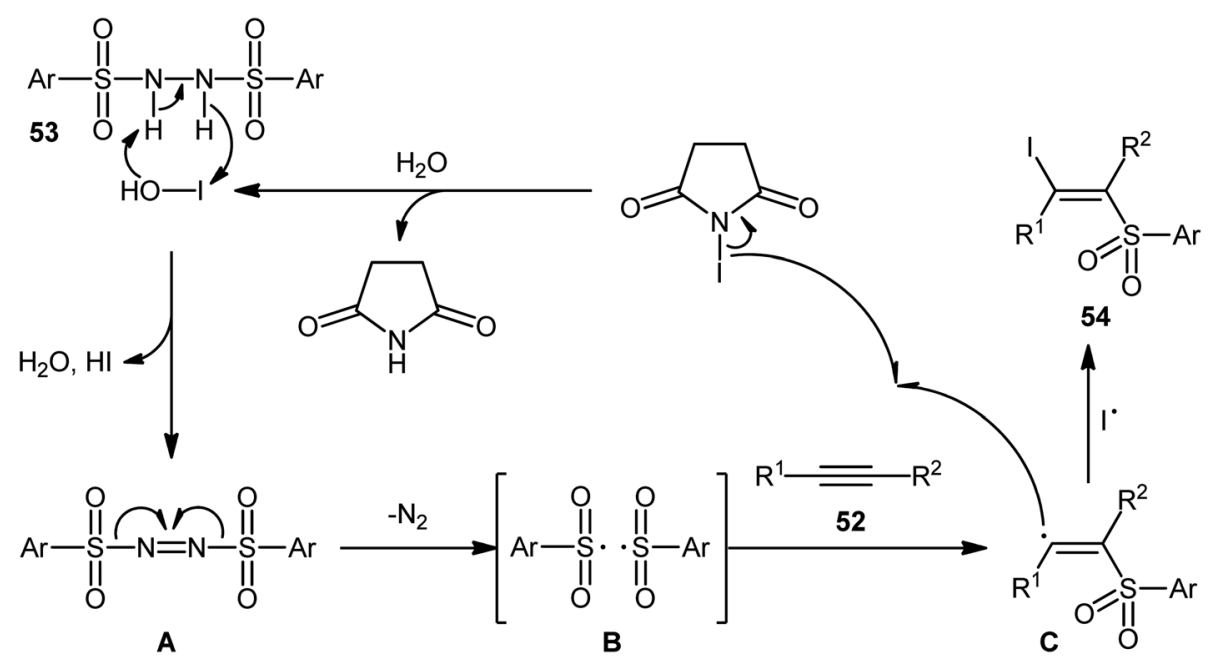

Scheme 23 Mechanism that accounts for the generation of $(E)$ - $\beta$-iodovinyl sulfones 54 . 


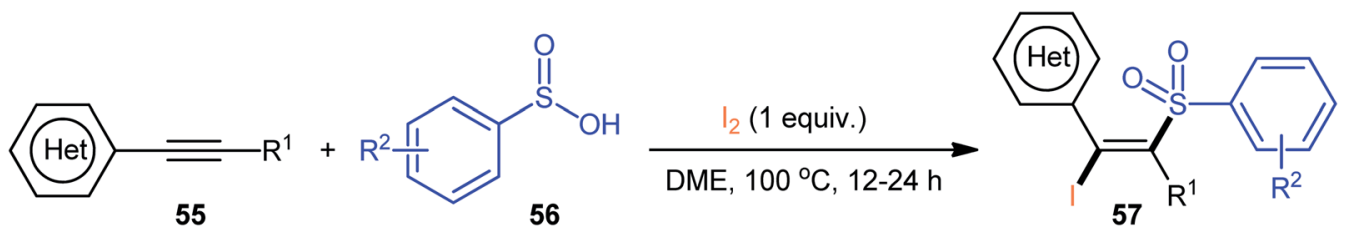

(Het)Ar= $\mathrm{Ph}, 4-\mathrm{Me}-\mathrm{C}_{6} \mathrm{H}_{4}, 4-\mathrm{Ph}-\mathrm{C}_{6} \mathrm{H}_{4}, 4-\mathrm{OMe}-\mathrm{C}_{6} \mathrm{H}_{4}, 4-\mathrm{F}-\mathrm{C}_{6} \mathrm{H}_{4}, 4-\mathrm{Cl}-\mathrm{C}_{6} \mathrm{H}_{4}$, $\mathrm{R}^{1}=\mathrm{H}, \mathrm{Me}$ 4-Br- $\mathrm{C}_{6} \mathrm{H}_{4}, 4-\mathrm{CN}-\mathrm{C}_{6} \mathrm{H}_{4}, 3-\mathrm{Me}-\mathrm{C}_{6} \mathrm{H}_{4}, 1$-naphthyl, 3-thienyl

20 examples $(62-90 \%)$

$\mathrm{R}^{2}=\mathrm{H}, 4-\mathrm{Me}, 4-\mathrm{Cl}, 4-\mathrm{CF}_{3}, 2-\mathrm{Br}, 2-\mathrm{CF}_{3}, 3,4-(\mathrm{CH}=\mathrm{CH})_{2^{-}}$

Scheme 24 Wang's synthesis of $(E)$ - $\beta$-iodovinyl sulfones 57 .

iodosulfonylation reaction to internal alkynes by preforming the process in the presence of over-stoichiometric amounts of $\mathrm{H}_{2} \mathrm{O}_{2}$ using $\mathrm{KI}$ as iodine source. ${ }^{48}$ Interestingly, when the same reaction was performed in 2,2,2-trifluoroethanol (TFE), aggregation induced-emission (AIE)-active benzo[b]thiophene-1,1dioxides were obtained instead of the desired iodovinyl sulfones through intra-molecular cyclization of the vinyl radical intermediate (generated from the addition of sulfonyl radical to alkyne). Along this line, Wei and Wang along with their colleagues demonstrated the synthesis of multisubstituted $\alpha, \beta-$ enones through the direct selective iodosulfonylation of alkylynones with arylsulfonyl hydrazides and iodine pentoxide $\left(\mathrm{I}_{2} \mathrm{O}_{5}\right) \cdot{ }^{49}$

Very recently, the group of Wang and $\mathrm{Hu}$ informed for the first time the usefulness of $N, N^{\prime}$-disulfonylhydrazines as novel sulfonylating reagents for halosulfonylation reactions. ${ }^{50}$ Thus, in the absence of any catalyst or additive in aqueous THF at room temperature, the reaction of various terminal and internal alkynes $\mathbf{5 2}$ with $N, N^{\prime}$-disulfonylhydrazines $\mathbf{5 3}$ and NIS furnished the corresponding $(E)$ - $\beta$-iodovinyl sulfones $\mathbf{5 4}$ in moderate to excellent yields within only $5 \mathrm{~min}$ (Scheme 22). Indeed, NIS played a dual role in this transformation; the iodine source and the oxidant. Mechanistically, the reaction starts with the formation of HOI oxidant through the hydrolysis of NIS by $\mathrm{H}_{2} \mathrm{O}$, which subsequently oxidizes $N, N^{\prime}$-disulfonyl-hydrazine $\mathbf{5 3}$ into the corresponding azo-intermediate A. Next, this intermediate undergoes a spontaneous decomposition to give two sulfonyl radicals B. Thereafter, the newly formed radical selectively attacks to the less hindered end of alkyne $\mathbf{5 2}$ to yield a vinyl radical $\mathbf{C}$ that, after getting an iodine radical from NIS affords the expected products 54 (Scheme 23).

4.2.3. Miscellaneous reactions. In 2015, the Wang group realized that sulfinic acids could serve as good sulfonyl sources in halosulfonylation reactions of alkynes. ${ }^{51}$ They showed that three-component reaction between aromatic alkynes 55, sulfinic acids 56, and molecular iodine in the absence of any catalyst or additive formed a series corresponding $(E)$ - $\beta$-iodovinyl sulfones $\mathbf{5 7}$ in good to excellent yields with outstanding stereo- and regio-selectivities (Scheme 24). Of note, propiolates could also be participated in this reaction, albeit with lower efficiencies. However, when 1-hexyne (an aliphatic alkyne) was employed under the identical reaction conditions, the desired product was isolated obtained in only $12 \%$ yield. Interestingly, when the reactions were performed in the presence of stoichiometric amounts of $\mathrm{K}_{2} \mathrm{CO}_{3}$, the corresponding acetylenic sulfones were obtained in high yields. Based on a series of control experiments, a plausible mechanism was suggested for the formation of $(E)$ - $\beta$-iodovinyl sulfones, as depicted in Scheme 25. Initially, the sulfinic acid $\mathbf{5 6}$ was oxidized by air oxygen to form the sulfonyl radical A, followed by addition to alkyne $\mathbf{5 5}$ to generate the alkenyl radical B. Finally, the interaction of intermediate $\mathbf{B}$ with molecular iodine delivered the desired $\beta$-iodovinyl sulfone 57 (Scheme 25, path a). In another possibility, the direct iodosulfonylation of alkyne $\mathbf{5 5}$ with in situ generated sulfonyl iodides $\mathbf{C}$ (from sulfinic acid $\mathbf{5 6}$ and molecular iodine) led to the formation of the target products 57 (Scheme 25, path b).

Recently, in a significant contribution in this field, Pan and Liu developed an efficient four-component synthesis of $(E)-\alpha-$

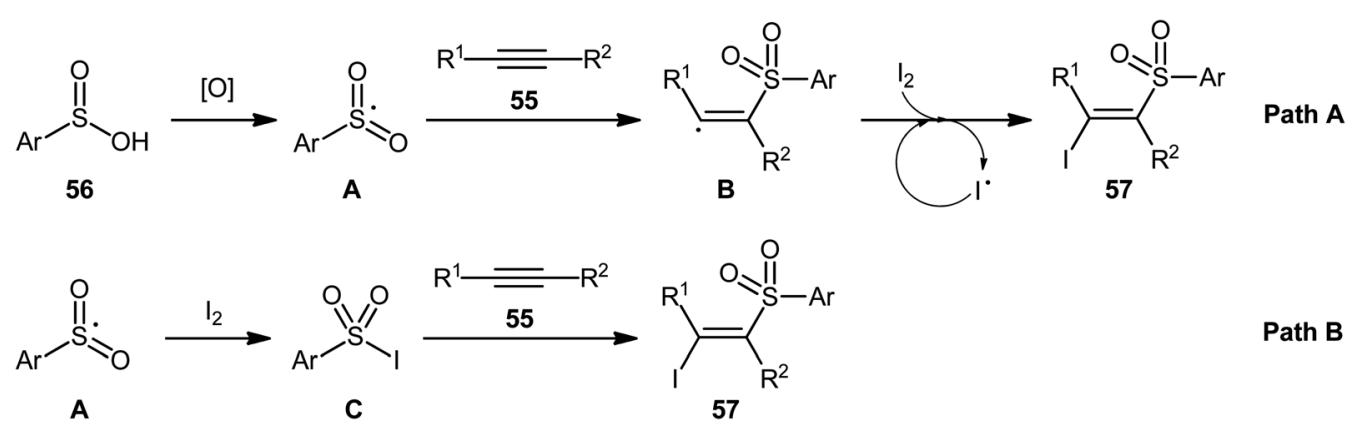

Scheme 25 Possible reaction pathway for the formation $(E)$ - $\beta$-iodovinyl sulfones 57. 


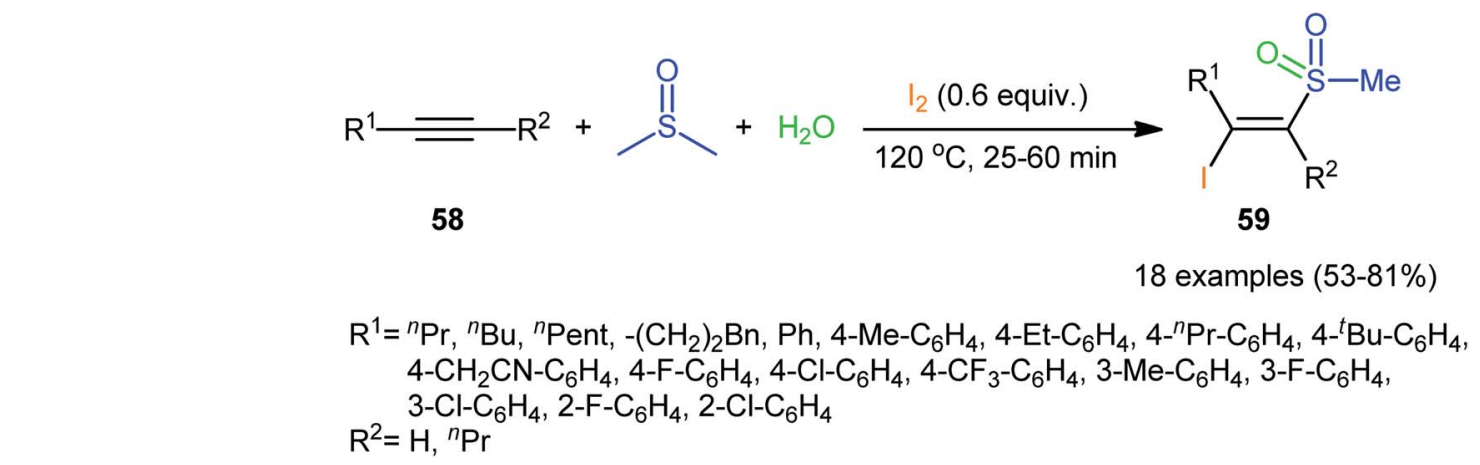

Scheme 26 Catalyst-free four-component synthesis of $(E)$ - $\alpha$-iodo- $\beta$-methylsulfonylalkenes 59 from alkynes $58, \mathrm{DMSO}, \mathrm{I}_{2}$, and $\mathrm{H}_{2} \mathrm{O}$.

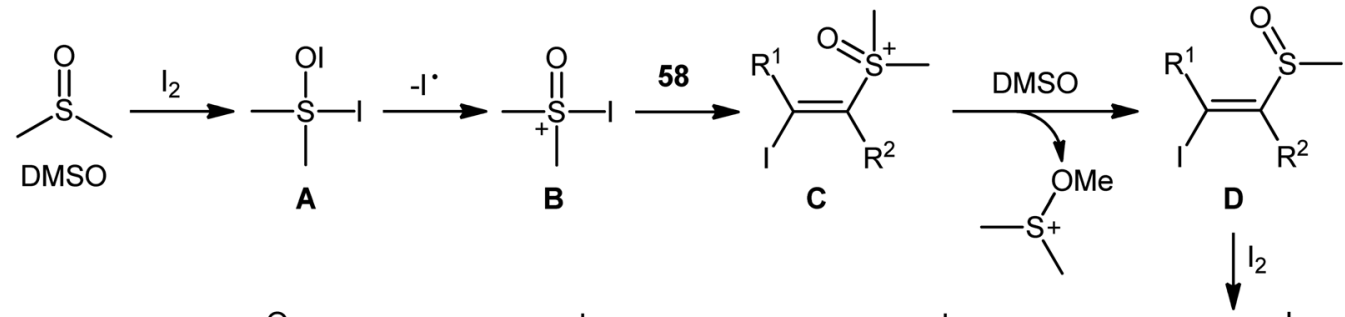<smiles>[R]C(I)=C([R])S(C)(=O)=O</smiles>

59

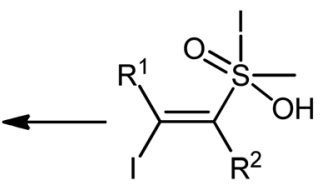

G
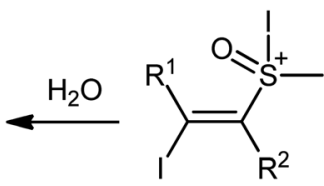

$\mathbf{F}$

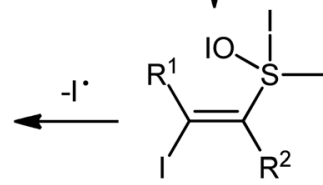

E

Scheme 27 Possible pathway of $(E)$ - $\alpha$-iodo- $\beta$-methylsulfonylalkenes 59 formation.

iodo- $\beta$-methylsulfonylalkenes $\mathbf{5 9}$ from alkynes $\mathbf{5 8}$, dimethyl sulfoxide (DMSO), molecular iodine and water without any added catalyst and solvent (Scheme 26). ${ }^{52}$ This eco-friendly synthetic strategy is distinguished by its generality, accommodating aliphatic and aromatic terminal alkynes, and even internal alkyl-alkyl alkynes in the presence of various sensitive functional groups (e.g., $\mathrm{F}, \mathrm{Cl}, \mathrm{CF}_{3}, \mathrm{CN}$ ). A possible mechanism for this transformation was proposed by the authors, as shown in Scheme 27.

Finally, it should be noted that transition metals play main role in direct halosulfonylation of alkynes..$^{53-61}$

\section{Conclusion}

Difunctionalization of alkyne feedstocks is a specific class of important synthetic transformations that allow for the buildup of molecular complexity within a single click. ${ }^{62}$ In this context, the direct halosulfonylation of alkynes which provide a powerful strategy for the preparation of $\beta$-halovinyl sulfone derivatives has devoted a great deal of attention. As illustrated, most of the halosulfonylation reaction of alkynes were performed under catalyst- and additive-free conditions. Despite the remarkable progress that has been achieved in this interesting research arena, some challenging problems remain unsolved yet. For example: (i) generally, the regioselectivity of reactions is dominated by the Markovnikov-type products. Thus, many more studies are further needed to development of efficient procedures that allow halosulfonylation reactions in an antiMarkovnikov-type manner; (ii) the number of reported examples in bromosulfonylation reactions are very narrow and, of course, there is a need to study the scope and limitations of these reactions; and (iii) fluorosulfonylation of alkynes should be explored.

\section{Conflicts of interest}

There are no conflicts to declare.

\section{Acknowledgements}

This work was sponsored by Hanshan Normal University.

\section{References}

1 (a) D. C. Meadows and J. Gervay-Hague, Med. Res. Rev., 2006, 26, 793-814; (b) M. A. Alam, K. Shimada, A. Jahan, M. W. Khan, M. M. Bhuiyan, M. S. Alam and M. M. Matin, Nat. Prod. Chem. Res., 2018, 6, 4-11; (c) M. Feng, B. Tang, S. H. Liang and X. Jiang, Curr. Top. Med. Chem., 2016, 16, 1200-1216.

2 K. A. Scott and J. T. Njardarson, Top. Curr. Chem., 2019, 376, 5. 
3 (a) N. W. Liu, S. Liang and G. Manolikakes, Synthesis, 2016, 48, 1939-1973; (b) A. N. R. Alba, X. Companyó and R. Rios, Chem. Soc. Rev., 2010, 39, 2018-2033; (c) E. N. Prilezhaeva, Russ. Chem. Rev., 2000, 69, 367-408.

4 (a) K. M. Short and C. B. Ziegler Jr, Tetrahedron Lett., 1995, 36, 355-356; (b) R. J. Reddy, J. J. Kumar, A. H. Kumari and G. R. Krishna, Adv. Synth. Catal., 2020, 362, 1317-1322.

5 (a) R. J. Reddy, J. J. Kumar and A. H. Kumari, Eur. J. Org. Chem., 2019, 3771-3775; (b) S. H. Suzol, A. H. Howlader, Z. Wen, Y. Ren, E. E. Laverde, C. Garcia, Y. Liu and S. F. Wnuk, ACS Omega, 2018, 3, 4276-4288.

6 Y. Liang, S. H. Suzol, Z. Wen, A. G. Artiles, L. Mathivathanan, R. G. Raptis and S. F. Wnuk, Org. Lett., 2016, 18, 1418-1421.

7 X. X. Gu, M. H. Xie, X. Y. Zhao, Y. Sun, W. Zhang, F. D. Xie and S. W. Wang, Chin. J. Chem., 2008, 26, 1625-1629.

8 N. Iwata, T. Morioka, T. Kobayashi, T. Asada, H. Kinoshita and K. Inomata, Bull. Chem. Soc. Jpn., 1992, 65, 1379-1388.

9 J. R. Bull, N. S. Desmond-Smith, S. J. Heggie, R. Hunter and F. C. Tien, Synlett, 1998, 900-902.

10 (a) X. Huang, D. Duan and W. Zheng, J. Org. Chem., 2003, 68, 1958-1963; (b) R. R. Wolff, V. Basava, R. M. Giuliano, W. J. Boyko and J. H. Schauble, Can. J. Chem., 2006, 84, 667-675.

11 Y. Fang, Z. Luo and X. Xu, RSC Adv., 2016, 6, 59661-59676.

12 Selected reviews: $(a)$ A. Hosseinian, S. Ahmadi, F. A. H. Nasab, R. Mohammadi and E. Vessally, Top. Curr. Chem., 2018, 376, 1-32; (b) X. G. Liang, J. S. Hua, S. Xiangdong and F. Behmagham, J. Fluorine Chem., 2020, 235, 109524; (c) A. Bakhtiary, M. R. P. Heravi, A. Hassanpour, I. Amini and E. Vessally, RSC Adv., 2021, 11, 470-483; (d) M. R. J. Sarvestani, N. Mert, P. Charehjou and E. Vessally, J. Chem. Lett., 2020, 1, 93-102; (e) L. Sreerama, E. Vessally and F. Behmagham, J. Chem. Lett., 2020, 1, 9-18; (f) S. Majedi, L. Sreerama, E. Vessally and F. Behmagham, J. Chem. Lett., 2020, 1, 25-31.

13 Z. Liu, A. Ebadi, M. Toughani, N. Mert and E. Vessally, RSC $A d v .$, 2020, 10, 37299-37313.

14 A. Hassanpour, M. R. P. Heravi, A. Ebadi, A. Hosseinian and E. Vessally, J. Fluorine Chem., 2021, 245, 109762.

15 W. Xu, D. Guo, A. G. Ebadi, M. Toughani and E. Vessally, J. CO2 Util., 2021, 45, 101403.

16 X. Wang, W. Ping, A. G. Ebadi, S. Majedi, Z. Hossaini and M. Toughani, J. CO2 Util., 2021, 50, 101592.

17 X. Ma, Z. Kexin, W. Yonggang, A. G. Ebadi and M. Toughani, Iran. J. Chem. Chem. Eng., 2021, 40, 1364-1374.

18 S. Ahmadi, A. Hosseinian, P. D. Kheirollahi Nezhad, A. Monfared and E. Vessally, Iran. J. Chem. Chem. Eng., 2019, 38, 1-19.

19 E. Vessally, S. Mohammadi, M. Abdoli, A. Hosseinian and P. Ojaghloo, Iran. J. Chem. Chem. Eng., 2020, 39, 11-19.

20 Y. Liu, A. G. Ebadi, L. Youseftabar-Miri, A. Hassanpour and E. Vessally, RSC Adv., 2019, 9, 25199-25215.

21 Y. Amiel, J. Org. Chem., 1971, 36, 3697-3702.

22 Y. Amiel, Tetrahedron Lett., 1971, 12, 661-663.

23 X. Liu, X. Duan, Z. Pan, Y. Han and Y. Liang, Synlett, 2005, 1752-1754.
24 X. Zeng, L. Ilies and E. Nakamura, Org. Lett., 2012, 14, 954956.

25 L. Wang, H. Zhu, J. Che, Y. Yang and G. Zhu, Tetrahedron Lett., 2014, 55, 1011-1013.

26 P. Chakrasali, K. Kim, Y. S. Jung, H. Kim and S. B. Han, Org. Lett., 2018, 20, 7509-7513.

27 A. Hossain, S. Engl, E. Lutsker and O. Reiser, ACS Catal., 2018, 9, 1103-1109.

28 M. Alkan-Zambada and X. Hu, J. Org. Chem., 2019, 84, 45254533.

29 X. Li, X. Shi, M. Fang and X. Xu, J. Org. Chem., 2013, 78, 94999504.

30 K. Zeng, L. Chen, Y. Chen, Y. Liu, Y. Zhou, C. T. Au and S. F. Yin, Adv. Synth. Catal., 2017, 359, 841-847.

31 Y. Amiel, J. Org. Chem., 1974, 39, 3867-3870.

32 V. Vasin, I. Bolusheva and V. Razin, Sulfur Lett., 2003, 26, 101-107.

33 N. Taniguchi, Synlett, 2011, 1308-1312.

34 Y. Gao, W. Wu, Y. Huang, K. Huang and H. Jiang, Org. Chem. Front., 2014, 1, 361-364.

35 W. E. Truce and G. C. Wolf, J. Org. Chem., 1971, 36, 17271732.

36 C. M. da Silva Corrêa and M. D. C. Fleming, J. Chem. Soc., Perkin Trans. 2, 1987, 103-107.

37 Y. Hou, L. Zhu, H. Hu, S. Chen, Z. Li, Y. Liu and P. Gong, New J. Chem., 2018, 42, 8752-8755.

38 V. Nair, A. Augustine, T. G. George and L. G. Nair, Tetrahedron Lett., 2001, 42, 6763-6765.

39 V. Nair, A. Augustine and T. D. Suja, Synthesis, 2002, 22592265.

40 Y. Sun, A. Abdukader, D. Lu, H. Zhang and C. Liu, Green Chem., 2017, 19, 1255-1258.

41 W. Bi, C. Ren, L. Jia, X. Xia, X. Chen, X. Chen and Y. Zhao, Phosphorus, Sulfur Silicon Relat. Elem., 2017, 192, 391-396.

42 R. Kumar, V. Dwivedi and M. S. Reddy, Adv. Synth. Catal., 2017, 359, 2847-2856.

43 J. Zhang, Z. Liang, J. Wang, Z. Guo, C. Liu and M. Xie, ACS Omega, 2018, 3, 18002-18015.

44 N. Taniguchi, Tetrahedron, 2018, 74, 1454-1460.

45 X. Li, X. Xu and X. Shi, Tetrahedron Lett., 2013, 54, 30713074.

46 L. Yang, D. Hu, L. Wei and Y. Liu, Phosphorus, Sulfur Silicon Relat. Elem., 2017, 192, 1301-1304.

47 C. Tong, B. Gan, Y. Yan and Y. Y. Xie, Synth. Commun., 2017, 47, 1927-1933.

48 Y. Ma, K. Wang, D. Zhang and P. Sun, Adv. Synth. Catal., 2019, 361, 597-602.

49 H. H. Cui, C. L. He, D. S. Yang, H. L. Yue, W. Wei and H. Wang, Synlett, 2018, 29, 830-834.

50 D. Luo, L. Min, W. Zheng, L. Shan, X. Wang and Y. Hu, Chin. Chem. Lett., 2020, 31, 1877-1880.

51 W. Wei, J. Wen, D. Yang, H. Jing, J. You and H. Wang, RSC Adv., 2015, 5, 4416-4419.

52 P. Zhou, Y. Pan, H. Tan and W. Liu, J. Org. Chem., 2019, 84, 15662-15668.

53 Q. Hu, W. Zhang, Q. Yin, Y. Wang and H. Wang, Spectrochim. Acta, Part A, 2021, 244, 118864. 
54 H. Zhang, W. Guan, L. Zhang, X. Guan and S. Wang, ACS Omega, 2020, 5, 18007-18012.

55 L. Zhang, M. Zhang, S. You, D. Ma, J. Zhao and Z. Chen, Sci. Total Environ., 2021, 780, 146505.

56 M. Zou, Y. Qi, R. Qu, G. Al-Basher, X. Pan, Z. Wang and F. Zhu, Sci. Total Environ., 2021, 771, 144743.

57 W. Cao, N. Wu, R. Qu, R. C. Sun, Z. Huo, J. S. Ajarem and F. Zhu, Environ. Sci. Pollut. Res., 2021, 28, 31301-31311.

58 Z. Chen, H. Zhang, X. He, G. Fan, X. Li, Z. He, Z. He, G. Wang and L. Zhang, BioResources, 2021, 16, 2644-2654.
59 Z. Farasat, R. Panahi and B. Mokhtarani, Water Conservation and Management, 2017, 1, 7-9.

60 H. Zhang, M. Sun, L. Song, J. Guo and L. Zhang, Biochem. Eng. J., 2019, 147, 146-152.

61 W. Zhang, Y. Hu, J. Liu, H. Wang, J. Wei, P. Sun, L. Wu and H. Zheng, Saudi J. Biol. Sci., 2020, 27, 1667-1673.

62 (a) H. Yao, W. Hu and W. Zhang, Molecules, 2021, 26, 105; (b) H. Mei, Z. Yin, J. Liu, H. Sun and J. Han, Chin. J. Chem., 2019, 37, 292-301. 